\title{
Phosphorus status of pastoral soils where reactive phosphate rock fertilisers have been used
}

\author{
K.W. PERROTT, B.E. KERR, J.H. WATKINSON and J.E. WALLER \\ AgResearch, Ruakura Research Centre, Private Bag 3123, Hamilton
}

\begin{abstract}
The dissolution rate of Sechura phosphate rock (particle size 75-150 pm) was determined at 95 New Zealand sites with a range of soil and environmental properties. Rates ranged from 0 to $70 \%$ of the phosphate rock dissolved per year with an average dissolution rate of $31 \%$ /year. An initial model based on stepwise linear regression analysis indicated that the rate of dissolution was negatively associated with soil $\mathrm{pH}$ and positively associated with rainfall and exchangeable soil magnesium. There was also an effect of soil type and drainage. The amount of residual RPR accumulated from previous fertiliser application can be determined by a new soil test. This, together with the dissolution rate estimated from the nature of the RPR and the soil and site factors, can be used to indicate likely soil P status.
\end{abstract}

Keywords: dissolution, fertiliser, phosphorus, reactive phosphate rock, soil test

\section{Introduction}

Reactive phosphate rocks (RPRs) currently comprise $6.3 \%$ of the North Island fertiliser market. These are slow-release fertilisers in which the phosphate becomes available for plant uptake only as the fertiliser particles dissolve. The effectiveness of RPRs as direct application fertilisers depends, on their dissolution rates, which are themselves influenced by soil and environmental properties.

Although dissolution rates have been measured in laboratory incubations, these studies are influenced by the build-up of reaction products (phosphate and calcium). This, together with the lack of plants and absence of environmental effects such as rainfall, limits the use of these studies for determining dissolution rates of RPR in the field.

Numerous field investigations have been made of RPR effectiveness over the last 30 years, including the National Series of Forms of Phosphate Fertiliser Trials. Edmeades et al. (1991) summarised these trials and used them as a basis for recommending guidelines for
RPR use. However, the trial data were limited to a relatively narrow range of soils and environments. More extensive field investigation of the effects of soil and environment on the dissolution rate of RPR is required to provide more comprehensive guidelines for RPR use.

Determination of soil $\mathrm{P}$ status has been a problem where RPR fertilisers have been used. This is because the Olsen P test used in New Zealand for assessing soil $\mathrm{P}$ status does not detect residual RPR in the soil and can therefore underestimate soil P status (Perrott et al. 1993). Two new soil tests which include residual RPR have been proposed. These are the iron oxideimpregnated paper (Pi) test (Menon et al. 1989) and the mixed anion- and cation-exchange membrane test (Saggar et al. 1990). However, full evaluation and calibration of these tests would require a large number of field trials at sites with varied fertiliser history covering use of both superphosphate and RPR, and differing RPR application times. The influence on these tests of soil and climatic factors, which effect RPR dissolution rates, would also need evaluation. Because of the time and experience invested in the Olsen test by New Zealand laboratories, scientists and consultants, it is unlikely to be replaced by one of the new tests without thorough evaluation and accumulation of experience with the new test.

Another approach is to continue with the Olsen test but determine the amount of residual RPR in soil and calculate its contribution to soil P status (Perrott $\boldsymbol{e}$ t al. 1993). A new soil test for RPR residues in soils has been developed (Perrott \& Wise 1995) and is offered by the AgResearch Soil Fertility Service, The test enables the amount of residual RPR accumulated in soil as a result of previous fertiliser applications to be determined. However, interpretation of test values required for fertiliser advice requires knowledge of the dissolution rate of RPR in the soil.

This paper summarises results obtained from field trials designed to determine effects of soil and environmental factors on RPR dissolution rates in soil. The paper also describes the use of the RPR test for estimating the contribution of residual RPR to soil $\mathrm{P}$ status. 


\section{Methods}

\section{Sites and treatments}

Ninety-eight pastoral sites were selected from throughout New Zealand to provide the diversity in soil and environmental factors influencing RPR dissolution (Table 1). Paired plots $(1 \mathrm{~m} \times 3 \mathrm{~m})$ were laid down at each site to provide two replicate fertilised plots and two replicate unfertilised plots. Sechura phosphate rock (PR) (75-150 $\mu \mathrm{m}$ particle size) was applied to the fertilised plots at a rate of $100 \mathrm{~kg} \mathrm{P} / \mathrm{ha}$. The sites were maintained under grazing management (either dairy, sheep or beef) for 2 years. No herbage measurements were made.

Table 1 Some soil and site characteristics for the 98 selected sites.

\begin{tabular}{lccc}
\hline & Average & Minimum & Maximum \\
\hline Rainfall (mm/year) & 1270 & 350 & 4320 \\
Bulk density $\left(\mathrm{g} / \mathrm{cm}^{3}\right)$ & 0.85 & 0.20 & 1.28 \\
Olsen P & 17 & 3 & 137 \\
QT Ca & 7.7 & 1.0 & 19.3 \\
pH & 5.7 & 4.9 & 6.4 \\
Phosphate retention (\%) & 40 & 2 & 98 \\
CEC (meq/100 g) & 13.6 & 3.5 & 41.2 \\
Exchangeable Ca (meq/100 g) & 9.5 & 0.7 & 35.3 \\
Exchangeable K (meq/100 g) & 0.64 & 0.19 & 3.13 \\
Exchangeable Mg (meq/100 g) & 1.75 & 0.25 & 6.01 \\
Exchangeable Na (meq/100 g) & 0.28 & 0.02 & 1.17 \\
\% Exchangeable Ca (\%) & 67 & 20 & 92 \\
Lime requirement & 1.9 & -1.3 & 5.0 \\
Topography & 62 flat, 28 sloping \& 8 hilly \\
Soil type & 64 Sedimentary, 22 Ash, 4 Peat \& 8 Pumice \\
\hline
\end{tabular}

a As used by AgResearch Soil Fertility Service.

\section{Soil sampling}

Soil samples (15 cores, $25 \mathrm{~mm}$ diam. O-75 mm depth) were taken immediately before and immediately after fertiliser application. The plots for both treatments were then sampled $(\mathrm{O}-75 \mathrm{~mm})$ at 2-monthly intervals for 12 months and thereafter at 3-monthly intervals for another 12 months. In addition, soil samples were taken from the $75-150 \mathrm{~mm}$ depth immediately before fertiliser application and at 12 and 24 months.

\section{Chemical analyses}

Soil chemical measurements (Table 1) were made on samples collected before fertiliser application. Residual PR-P was determined using a sequential extraction procedure (Perrott \& Kerr 1994). In this method phosphate extracted by sulphuric acid (acid-P), after prior removal of alkali soluble $\mathrm{P}$, is determined for both fertilised and unfertilised soils and residual PR-P calculated by difference (Perrott \& Kerr 1994).

\section{Mathematical analyses}

The rate constants were calculated for individual sites. There was little evidence of any changes in acid-P in the control plots over time, so these were averaged and the average subtracted from the acid-P for the fertilised plots. These residual levels of applied $\mathrm{P}$ for both the treated plots were then regressed against time using the dissolution model developed by Watkinson (1994a; 1994b), allowing for different intercepts for the two plots, to obtain the rate constant. The dissolution model was fitted using the non-linear routine of Genstat (Rothamsted Experimental Station 1993).

\section{Results}

\section{Movement of PR below $75 \mathrm{~mm}$}

Increases in acid-P below $75 \mathrm{~mm}$ in the fertilised plots (12 and 24 months compared with zero time) were not significant for individual sites. Averaged over all the sites the increase was significant, but small (7 and $10 \mu \mathrm{g} \mathrm{P} / \mathrm{g}$ at 12 and 24 months, respectively), compared with acid-P levels due to RPR in the upper $75 \mathrm{~mm}$ of the soil ( 80 to $670 \mu \mathrm{g} \mathrm{P} / \mathrm{g}$ ) (Table 2). Therefore, loss of RPR due to movement of particles below $75 \mathrm{~mm}$ was not considered in determining dissolution rates.

Table 2 Mean changes of acid $\mathrm{P}(\mu \mathrm{g} P / \mathrm{g})$ in $75-150 \mathrm{~mm}$ samples (averaged over 74 sites).

\begin{tabular}{|c|c|c|}
\hline Treatment & $12 \mathrm{months}$ & 24 months \\
\hline Fertilised & 7.2 & 10.4 \\
\hline Unfertilised & 1.7 & 0.9 \\
\hline SED & 2.46 & 2.09 \\
\hline
\end{tabular}

\section{Dissolution $r$ a $t$ e $s$}

Acid-P data for 4 of the sites are presented in Figure 1 as examples. The values for the unfertilised soil were significant compared with those for fertilised soils (Perrott \& Kerr 1994) and hence their subtraction was required in all cases. The situation for the Otanomdmo site (Figure 1), which was a peat soil, was exceptional.

The dissolution rates ranged from 0 to $70 \%$ of the rock dissolved per year, with an average rate of $31 \%$ /year (Figure 2). Data for 3 of the sites were not included because of various problems in those trials.

Correlation of dissolution rate constants with soil and site factors

The initial investigation was carried out using stepwise regression. Initial regressions indicated an association with topography, with the steeper sites having faster dissolution. Because of the possibility that this may 
have resulted from surface movement of fertiliser particles (i.e., RPR loss rather than dissolution), the 8 hilly sites were removed from the final regression analysis. This changes the average dissolution rate to $30 \% / y e a r$, with a maximum rate of $70 \%$ /year. The final model (which explained about $55 \%$ of the variation) indicated that the dissolution rate was associated with soil $\mathrm{pH}$, soil type, exchangeable $\mathrm{Mg}$, rainfall and drainage.

\section{Discussion}

\section{Dissolution rates}

Although movement of RPR below $75 \mathrm{~mm}$ was significant when averaged over all sites, the actual increase in acid-P below $75 \mathrm{~mm}$ was very small (Table 2) and was therefore not considered in determining dissolution rates.

The correlation of dissolution rate constants with $\mathrm{pH}$ (negative) and rainfall (positive) is consistent with previous findings (Edmeades et al. 1991). Drainage has a negative effect (dissolution is faster in poorly drained soils), confirming the positive influence of soil moisture on the dissolution rate. It is possible that exchangeable $\mathrm{Mg}$ indicates the ability of the soil to remove $\mathrm{Ca}$ from soil solution and therefore the positive correlation of dissolution rate constants with exchangeable $\mathrm{Mg}$ is a reflection of the enhancement of dissolution by removal of $\mathrm{Ca}$ from solution (Robinson \& Syers 1990; 199 1).

The distribution of dissolution rates given in Figure 2 is specific to Sechura PR with a particle size of 75$150 \mu \mathrm{m}$. The rate constants estimated from this model can be used to calculate dissolution rates for other RPRs, provided the solubility and particle size distribution are known (Watkinson 1994c). For example, for the four soils described in Table 3 the dissolution rate of "as received" Sechura PR is $8 \%$ to $20 \% /$ year compared with $12 \%$ to $32 \%$ /year for Sechura PR with a particle size range of 75-1 $50 \mu \mathrm{m}$ (Table 3).

Contribution of residual RPR to soil P status Estimation of the contribution of RPR residues to soil $\mathrm{P}$ status requires information on:

(a) the amount of residual RPR in the soil, and

(b) an estimate of its dissolution rate.

Residual RPR has been determined by P fractionation but it can also be determined using the recently developed routine RPR test (Perrott \& Wise 1995). Unlike the P fractionation procedures, the latter test does not require a soil sample from an unfertilised plot.
Figure 1 Dissolution of Sechura phosphate rock (particle size range of $75-150 \mathrm{pm}$ ) at four sites. (a) Oruanui (25\%/year); (b) Opua (7\%/year); (c) Oreti (20\%/year); (d) Otanomomo (45\%/year). (Symbols: control plots; - fertilised plots. Lines are fitted curve for fertilised plots and acid-P levels for samples taken from fertilised plots before fertiliser application).
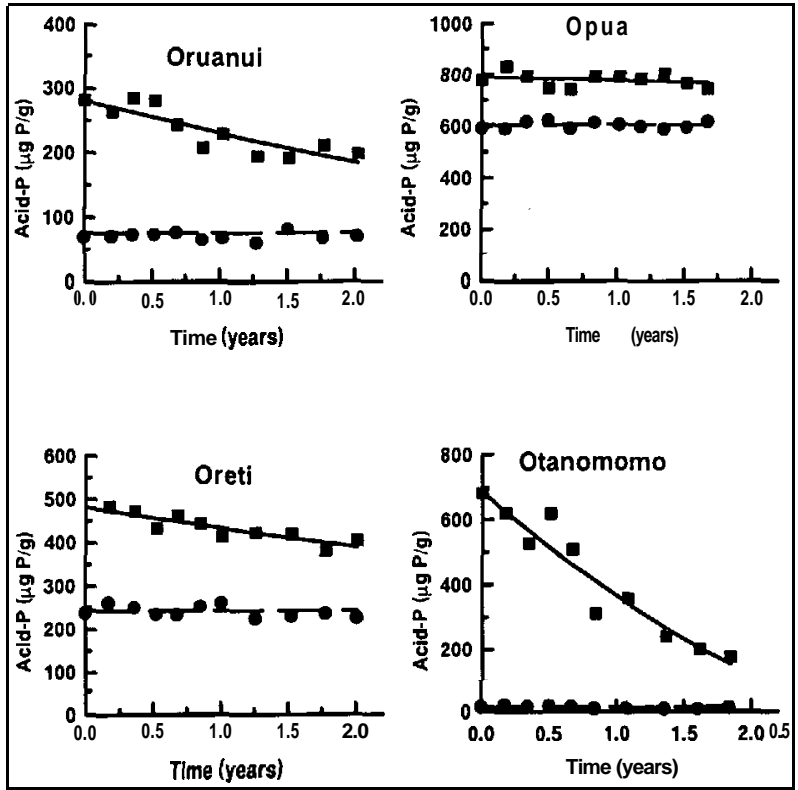

Figure 2 Distribution of the dissolution rates for Sechura phosphate rock with particle size range of 75-150 $\mu \mathrm{m}$ across the 92 sites.

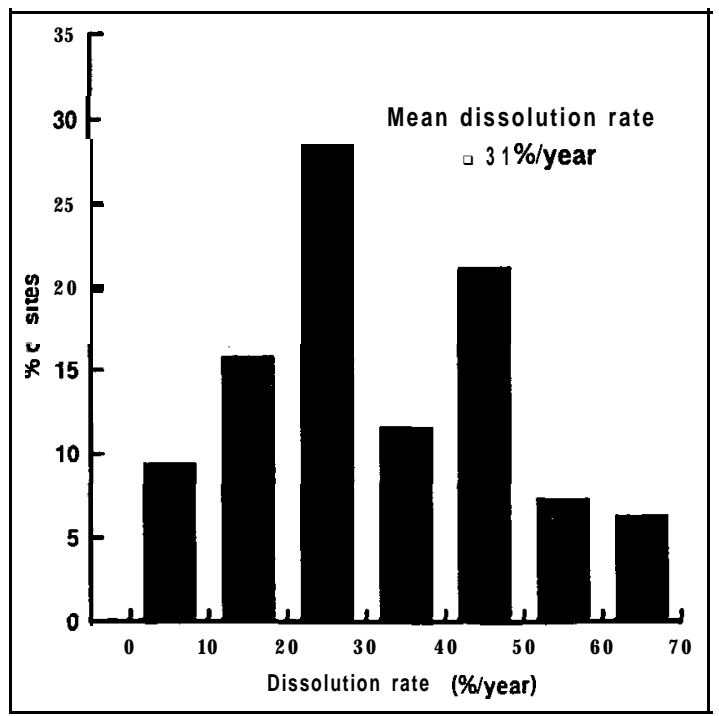


Table 3 Estimated dissolution rates and $\mathrm{P}$ release from Sechura phosphate rock in the 7 th year of four trials (Perrott $e t$ a. P92).

\begin{tabular}{|c|c|c|c|c|c|c|c|c|}
\hline Site & $\begin{array}{l}\text { Sechura } \\
\text { application rate }\end{array}$ & Olsen P & Annual y & DMina) & $\begin{array}{l}\text { Estimated diss } \\
\text {..... Sechura } P\end{array}$ & $\begin{array}{l}\text { lution rate for } \\
\{(\% / \text { year })\end{array}$ & $\begin{array}{l}\text { Residual } \\
\text { RPR }\end{array}$ & $\begin{array}{l}\text { Estimated } P \text { release } \\
\text { from residual RPR }\end{array}$ \\
\hline & (kg P/halyear) & $(\mu \mathrm{g} P / \mathrm{ml})$ & Predicted & Actual & $(75-150 \mathrm{~m})^{\mathrm{A}}$ & As received 8 & (kgP/ha) & (kg P/ha/year) C \\
\hline Puketona & Mean $^{\circ}$ & 16.8 & 6.12 & 8.93 & 27 & 17 & 100 & 17 \\
\hline & 33 & 16.7 & 6.21 & 6.85 & & & 100 & 17 \\
\hline & 66 & 16.3 & 8.20 & 9.36 & & & 150 & 25 \\
\hline Waitoa & Mean & 12.6 & 9.32 & 9.51 & 32 & 20 & 90 & 16 \\
\hline & 35 & 14.3 & 9.45 & 10.46 & & & 70 & 14 \\
\hline & 70 & 14.3 & 9.45 & 11.57 & & & 190 & 37 \\
\hline Te Kuiti & Mean & 7.0 & 6.76 & 10.71 & 12 & 8 & 70 & 5 \\
\hline & 37 & 7.0 & 6.76 & 9.82 & & & 80 & 6 \\
\hline & 74 & 9.0 & 9.20 & 10.66 & & & 240 & 18 \\
\hline Winchmore & Mean & 4.6 & 7.46 & 6.53 & $27^{E}$ & $17 \mathrm{E}$ & 30 & 5 \\
\hline & 20 & 4.3 & 7.13 & 6.55 & & & 20 & 4 \\
\hline & 40 & 6.3 & 8.76 & 9.59 & & & 70 & 12 \\
\hline
\end{tabular}

A Dissolution rate applies to Sechura phosphate rock with particle size range of $75-150 \mu \mathrm{m}$.

B For Sechura phosphate rock with particle size distribution reported by Smith et al. (1990).

C Calculated from residual RPR. estimated dissolution rate constant and assuming a similar particle size distribution to applied fertiliser.

D Values meaned over the four application rates, $0.5,0.75,1.0$ and $2.0 \times$ maintenance rate. The maintenance rates are $33,35,70$ and $20 \mathrm{~kg} P / \mathrm{ha} / \mathrm{year}$

for the Puketona, Waitoa, Te Kuiti and Winchmore sites respectively.

E Assumes a rainfall of $2000 \mathrm{~mm} /$ year to accommodate irrigation.

To demonstrate the use of the RPR test, residual RPR measurement and dissolution rate estimation were made for 4 field sites where Sechura PR and triple superphosphate (TSP) fertiliser had previously been applied annually for 6 years. The residual effectiveness of the RPR on dry matter production was measured in the 7th year (Perrott et al. 1992). Actual dry matter yields from the RPR treatments were first compared with predicted yields calculated from the Olsen P-values and the response curve for the TSP treatments (Table 3). In all cases Olsen $P$ underestimated pasture growth.

The dissolution rate constants for these sites were calculated from the soil $\mathrm{pH}$, soil exchangeable $\mathrm{Mg}$, soil type, rainfall and drainage. These constants were used to calculate dissolution rates for the standard phosphate rock (Sechura PR, 75-150 pm) used to measure dissolution rates at the 98 sites described above. The calculated rates are given in Table 3 and these values can be compared with those in Figure 2. However, in practice, RPR fertilisers have a wider ranges of particle sizes and this influences the dissolution rate. Therefore, dissolution rates, calculated using the method of Watkinson (1994c), are also given in Table 3 for the particle size distribution (45.4\% 75-150 pm, 49\% 150 $250 \mu \mathrm{m}, 4 \% 250-500 \mu \mathrm{m}$ and $1.6 \% 500-1000 \mathrm{pm}$ ) of the "as-received" Sechura PR used in these trials (Smith et al. 1990). These latter figures indicate the likely performance of Sechura PR fertiliser at these sites.

A detailed consideration of the calculated release of $\mathrm{P}$ over time from the residual RPR in the soil for RPRs currently on the New Zealand market indicates that it is warranted to assume that, for practical purposes, the residual RPR in the soil has a particle size distribution similar to that of the original fertiliser. Therefore, the particle size distribution of the "asreceived" fertiliser, together with the amount of residual $\mathrm{RPR}$, was used to estimate the release of $\mathrm{P}$ from the residual RPR in the soil (Table 3). These figures give an indication of the release of $P$ from the accumulated RPR residues in the soil. The data in Table 3 indicate that in most cases considerable amounts of $\mathrm{P}$ would have been released from the residual RPR. For example, where Sechura PR had been applied for 6 years at the maintenance rate the $\mathrm{P}$ released from the residual RPR ranged from $4-17 \mathrm{~kg}$ P/ha/year $(20-52 \%$ of the maintenance amount for soluble fertiliser). Where application had been at twice the maintenance rate the $\mathrm{P}$ released from the residual RPR ranged from 12-37 $\mathrm{kg} \mathrm{P} / \mathrm{ha} /$ year (equivalent to $60-106 \%$ of maintenance amount for soluble fertiliser). These amounts would probably account for the difference between the estimated and actual dry matter yields.

This approach assumes that the efficiency of $\mathrm{P}$ utilisation by pasture is the same for $\mathrm{P}$ dissolved from RPR as for the soluble P in TSP. Although there has been speculation of possible differences in efficiency, as yet no conclusive evidence has appeared. Such differences, if they occur, are probably too small to be measured in field experiments.

\section{Conclusions}

The dissolution rate of RPR at a specific site can be estimated from the fertiliser properties (RPR solubility and particle size distribution) and the soil and environmental factors (soil type, soil $\mathrm{pH}$, exchangeable 
soil $\mathrm{Mg}$, rainfall and drainage). If the amount and nature of residual RPR in the soil is known, its contribution to soil P status can be estimated.

\section{ACKNOWLEDGEMENTS}

This work was funded by a grant from the New Zealand Foundation for Science and Technology. We acknowledge the assistance of Amanda Judge, who co-ordinated the trials and the AgResearch field staff who laid down and sampled individual trials.

\section{REFERENCES}

Edmeades, D.C.; Watkinson, J.H.; Perrott, K.W.; Sinclair, A.G.; Ledgard, SF.; Rajan, S.S.S.; Brown, M.W.; Roberts, A.H.; Thorrold, B.T.; O'Connor, M.B.; Floate, M.J.S.; Risk, W.H.; Morton, J. 1991. Comparing the agronomic performance of soluble and slow release phosphate fertilisers: the experimental basis for RPR recommendations. Proceedings of the New Zealand Grassland Association 53: 18 1-1 90.

Menon, R.G.; Hammond, L.L.; Sissingh, H.A. 1989. Determination of plant-available phosphorus by the iron oxide-impregnated paper (Pi) soil test. Soil Science Society of America journal 53: 110-l 15.

Perrott, K.W.; Kerr, B.E. 1994. Determination of phosphate rock residues in acid soils. Transactions of the 15th International Soil Science Congress 5a: 230-243.

Perrott, K.W.; Roberts, A.H.C.; Saggar, S.; Shannon, P.W.; O'Connor, M.B.; Nguyen, L.; Risk, W.H. 1992. Pasture production and soil phosphorus fractions resulting from six previous annual applications of triple superphosphate or Sechura phosphate rock. New Zealandjournal of agricultural research 35: 307-3 19.

Perrott, K.W.; Saggar, S.; Menon, R.G. 1993. Evaluation of soil phosphate status where phosphate rock based fertilisers have been used. Fertilizer research 35: $67-82$.
Perrott, K.W.; Wise, R.G. 1995. A routine test for quantifying RPR residues in soil. In (Ed. L.D. Currie \& P. Loganathan.) Fertilizer requirements of grazed pastureandjieldcrops. Macro- andmicro-nutrients. Occasional Report No. 8. Fertilizer and 'Lime Research Centre, Massey University, Palmerston North, pp 85-100.

Rothamsted Experimental Station 1993. Genstat 5, release 2.2. Statistics Department, Rothamsted Experimental Station, Harpenden, Hertfordshire AL5 2JQ, England.

Robinson, J.S.; Syers, J.K. 1990. A critical evaluation of the factors influencing the dissolution of Gafsa phosphate rock. Journal of soil science 41: $597-$ 605.

Robinson, J.S.; Syers, J.K. 1991. Effects of solution calcium concentration and calcium sink size on the dissolution of Gafsaphosphate rock in soils. Journal of soil science 42: 389-397.

Saggar, S.; Hedley, M.J.; White, R.E. 1990. A simplified resin membrane technique for extracting phosphorus from soils. Fertilizer research 24: 173-1 80.

Smith, L.C.; Johnstone, P.D.; Sinclair, A.G.; Shannon, P.W.; O'Connor, M.B.; Percival, N.; Roberts, A.H.; Smith, R.G.; Mansell, G.; Morton, J.D.; Nguyen, L.; Dyson, C.B.; Risk, W.H. 1990. Final report on the MAF "National series" forms of phosphate fertiliser trials. Part 1: Description of the trials and annual herbage dry matter production. Ministry of Agriculture, Wellington, New Zealand.

Watkinson, J.H. 1994a. Modelling the dissolution rate of reactive phosphate rock in New Zealand pastoral soils. Australian journal of soil research 32: 739753.

Watkinson, J.H. 1994b. Dissolution rate of phosphate rock particles having a wide range of sizes. Australian journal of soil research 32: 1009-1014.

Watkinson, J.H. 1994c. A test for phosphate rock reactivity in which solubility and size are combined in a dissolution rate function. Fertilizer research 39: 205-2 15 . 